\title{
Kinetics and Photodegradation Study of Aqueous Methyl tert-Butyl Ether Using Zinc Oxide: The Effect of Particle Size
}

\author{
Zaki S. Seddigi, ${ }^{1}$ Saleh A. Ahmed, ${ }^{1}$ Shahid P. Ansari, ${ }^{1}$ Ekram Danish, ${ }^{2}$ \\ Abdullah Abu Alkibash, ${ }^{3}$ and Shakeel Ahmed ${ }^{4}$ \\ ${ }^{1}$ Chemistry Department, College of Applied Sciences, Umm Al-Qura University, Makkah 21955, Saudi Arabia \\ ${ }^{2}$ Chemistry Department, College of Sciences, King Abdulaziz University, Jeddah 21589, Saudi Arabia \\ ${ }^{3}$ Chemistry Department, College of Sciences, King Fahd University of Petroleum \& Minerals, Dhahran 31261, Saudi Arabia \\ ${ }^{4}$ Center for Refining \& Petrochemicals, Research Institute, King Fahd University of Petroleum \& Minerals, Dhahran 31261, Saudi Arabia
}

Correspondence should be addressed to Shahid P. Ansari; shahidzahir@gmail.com

Received 27 April 2013; Revised 24 July 2013; Accepted 25 August 2013

Academic Editor: Meenakshisundaram Swaminathan

Copyright (c) 2013 Zaki S. Seddigi et al. This is an open access article distributed under the Creative Commons Attribution License, which permits unrestricted use, distribution, and reproduction in any medium, provided the original work is properly cited.

Zinc oxide of different average particle sizes $25 \mathrm{~nm}, 59 \mathrm{~nm}$, and $421 \mathrm{~nm}$ as applied in the photodegradation of MTBE. This study was carried out in a batch photoreactor having a high pressure mercury lamp. Zinc oxide of particle size of $421 \mathrm{~nm}$ was found to be the most effective in degrading MTBE in an aqueous solution. On using this type of ZnO in a solution of $100 \mathrm{ppm}$ MTBE, the concentration of MTBE has decreased to $5.1 \mathrm{ppm}$ after a period of five hours. The kinetics of the photocatalytic degradation of MTBE was found to be a first order reaction.

\section{Introduction}

Fuel oxygenates like methyl tert-butyl ether (MTBE) are usually added for the complete combustion of gasoline. MTBE has low vapor pressure, high octane rate, very good blending compatibility with gasoline, and low production cost $[1,2]$. The speed of migration of MTBE resembles that of water and it has high resistance to biodegradation $[3,4]$. MTBE has been found to be a potential carcinogen; thus it poses serious health threats. The presence of MTBE can be easily detected in water even at very low concentrations from its characteristic smell which in turn lowers the quality of water. The serious hazardous effects of MTBE have attracted the attention of many researchers to develop efficient techniques that can be applied for the remediation/elimination of MTBE from water $[5,6]$. Those techniques include adsorption using activated carbon, biodegradation, and air-stripping; however, the results obtained were not satisfactory. For instance, the removal of MTBE by adsorption on activated carbon has been found to be ineffective because of the low adsorption of MTBE on the activated carbon. The adsorption process has been found to be costly because carbon has to be changed frequently [4]. Moreover, ethers are generally resistant to biodegradation because the presence of the bulky tertiary methyl group renders MTBE nonbiodegradable by the traditional methods [7-9].

Recently, advanced oxidation processes (AOPs) have been applied for the remediation of different contaminants in water. Complete oxidation of organic pollutants into $\mathrm{CO}_{2}$ and $\mathrm{H}_{2} \mathrm{O}$ can be achieved by applying AOPs. The application of AOPs in heterogeneous photocatalysis is highly promising and good results have been obtained when this type of photocatalysis was applied to treat nonbiodegradable toxic organic molecules that exist in water $[10,11]$. The heterogeneous photocatalytic reaction performed to degrade organic pollutants requires electromagnetic radiation of specific wave length, a catalyst (i.e., semiconducting metal oxide), and oxygen. The photocatalyst usually plays a very important role in carrying out the photochemical reaction. Being semiconductors in nature, photocatalysts have the tendency to promote their valence band electrons to conduction bands when they are subjected to an electromagnetic radiation of 
appropriate energy. The photoexcited electrons create holes when they jump to their corresponding conduction bands; therefore, the electron-hole pairs are generated in the semiconducting metal oxide photocatalyst. These photogenerated electrons/holes react with water/oxygen/hydroxyl ions to produce $\mathrm{OH}^{\bullet}$ radicals. The resulting $\mathrm{OH}^{\bullet}$ radicals react with the contaminant molecules adsorbed on the surface of the photocatalyst and act through a series of possible reactions to degrade those molecules to give $\mathrm{CO}_{2}$ and $\mathrm{H}_{2} \mathrm{O}$ [12-14].

The selection of an appropriate catalyst that will efficiently degrade the molecules of a certain pollutant is considered an important step. $\mathrm{TiO}_{2}$ and $\mathrm{ZnO}$ have attracted the attention of many researchers who have studied their applications as photocatalysts. This is due to the fact that these two catalysts are nontoxic, friendly with the environment, relatively inexpensive and their photogenerated holes are highly oxidizing in nature. However, in certain cases, $\mathrm{ZnO}$ has been found to be more effective than $\mathrm{TiO} 2$. $\mathrm{ZnO}$ has more active sites on its surface, as a result it will be more efficient in the photodegradation of dyes and more effective in generating $\mathrm{H}_{2} \mathrm{O}_{2}$ [14-17]. Recently, $\mathrm{ZnO}$ has been applied to treat water contaminated with MTBE [18].

This work reports, for the first time, the effect of the particle size of zinc oxide on the photodegradation of MTBE in aqueous medium. Zinc oxide of three different particle sizes having the averages of $420 \mathrm{~nm}, 59 \mathrm{~nm}$, and $25 \mathrm{~nm}$ were applied in this work.

\section{Materials and Methods}

2.1. Materials. Methyl tert-butyl ether (MTBE) of $99.9 \%$ purity was obtained from Sigma-Aldrich.

A stock solution of $100 \mathrm{ppm}$ of MTBE was prepared in distilled water.

Zinc oxide of different average particle sizes as used in this work. ZnO-1 of an average particle size of $421 \mathrm{~nm}$ was supplied by J.T. Baker, USA. Zinc oxide ( $\mathrm{ZnO}-2)$ of an average particle size of $25 \mathrm{~nm}$ was prepared by mixing the aqueous solution of the zinc nitrate hexahydrate and ammonium carbonate in a molar ratio of $1: 1$. This mixture was stirred at room temperature for a period of two hours. A precipitate was formed and separated by centrifugation. Zinc oxide of an average particle size of $59 \mathrm{~nm}$ was supplied by Nanoscale Materials Inc., USA. Samples of the three types of the zinc oxide were thoroughly washed with deionized water and then with ethanol and dried overnight at a temperature of $100^{\circ} \mathrm{C}$. The dried $\mathrm{ZnO}$ precursors were then calcined at $500^{\circ} \mathrm{C}$ for a period of six hours at a heating rate of $1^{\circ} \mathrm{C} / \mathrm{min}$ to obtain nano- $\mathrm{ZnO}$ particles. These particles were characterized by XRD, SEM, and TEM.

2.2. Photocatalytic Reaction Procedure. Methyl tert-butyl ether (MTBE) (reagent grade) from Aldrich was used without further purification in the photodegradation experiments. A photoreactor made of quartz and equipped with a cooling jacket and a specified tubular space for the UV lamp was used to perform the photodegradation experiments (Figure 1). A $125 \mathrm{~W}$ high pressure mercury UV lamp was placed in the

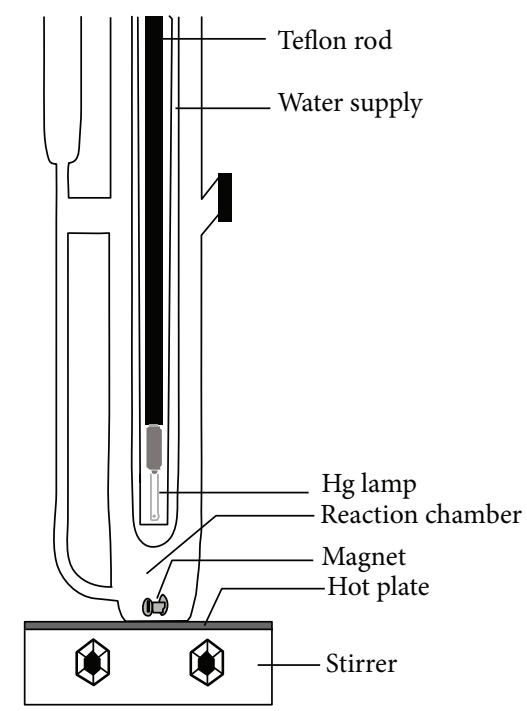

FIGURE 1: Photocatalytic experimental setup.

reactor in its specified space using a special rod. Cold water $\left(16 \pm 1^{\circ} \mathrm{C}\right)$ was continuously supplied through the cooling jacket to cool the reaction mixture. A volume of $350 \mathrm{~mL}$ of $100 \mathrm{ppm}$ MTBE solution and an amount of $100 \mathrm{mg}$ of each of the $\mathrm{ZnO}$ photocatalysts were added to the reactor and stirred for $30 \mathrm{~min}$. Stirring is essential in order to achieve uniform dispersion of the $\mathrm{ZnO}$ particles at room temperature. The oxygen gas was passed at a moderate flow rate through the reaction mixture for a period of $30 \mathrm{~min}$. After this time, the oxygen flow was stopped and the UV lamp was turned on. The reaction setup was covered with an aluminum foil and the samples were collected every hour for a period of five hours.

\section{Results and Discussion}

3.1. X-Ray Diffraction Studies. The XRD profiles of the three types of the $\mathrm{ZnO}$ photocatalysts used are shown in Figure 2. The XRD peaks observed in each spectrum indicate that the crystalline structures of the three types of the $\mathrm{ZnO}$ nanoparticles represent hexagonal wurtzite structure. X-ray diffraction pattern of different $\mathrm{ZnO}$ nanoparticles as obtained by X-ray diffractometer (X'pert PRO PANalytical) using $\mathrm{CuK}_{\alpha}$ radiation $(1.5406 \AA)$ in the range $2 \theta=10-80^{\circ}$ with 0.02 as step size at $25^{\circ} \mathrm{C}$. The existence of several peaks around $31.77525,34.41348,36.2,47.5,56.5,62.8,67.9$, and 69.1 corresponding to (100), (002), (101), (102), (110), (103), (112), and (201) planes can be observed. It is obvious from Figure 2 that the peaks are sharp and strong in nature, which indicates that the effect of the impurities is negligible [19, 20]. The average calculated sizes of the nanoparticles are in good agreement with the data obtained from the TEM micrographs.

3.2. Morphology of Photocatalysts. The morphology of each of the three types of the zinc oxide nanoparticles has been examined by means of the Field Emission Scanning Electron 


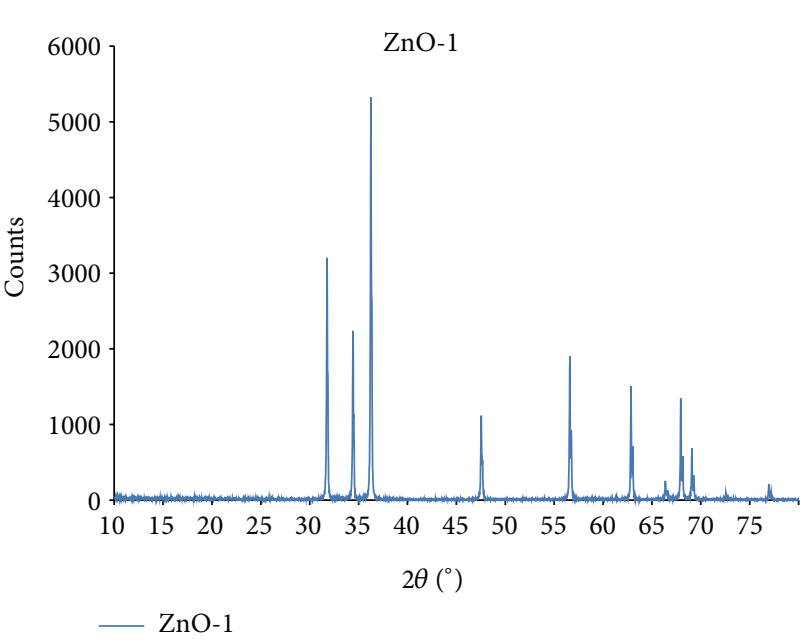

(a)

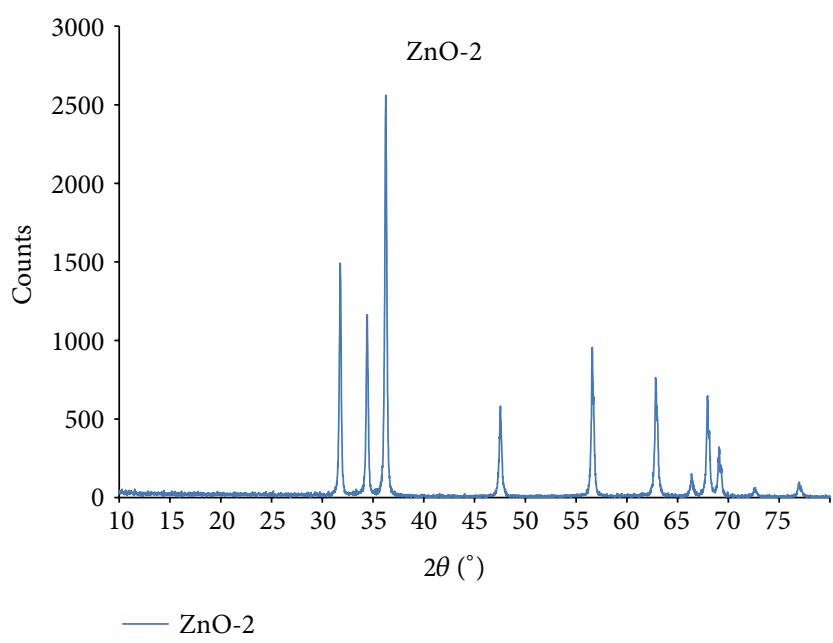

(b)

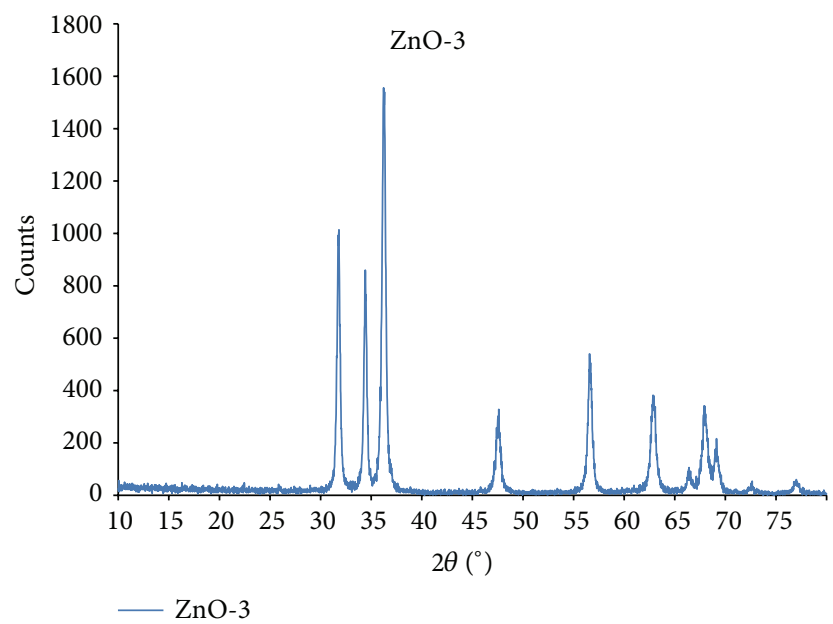

(c)

FIGURE 2: XRD spectrum of $\mathrm{ZnO}$ photocatalysts used.

Microscope (FESEM) and the Transmission Electron Microscope (TEM). The surface morphology and the crystallite structure of each powder of the photocatalysts used were analyzed using FESEM. Figure 3 shows that the three types of the $\mathrm{ZnO}$ nanoparticles used have different morphologies. Figure 3 also shows that the ranges of the sizes of the particles of these photocatalysts are different. It can be seen that the $\mathrm{ZnO}-1$ nanoparticles (Figure 3(a)) have cube or cuboid shapes of size ranges that are higher than the size ranges of the other two types and the $\mathrm{ZnO}-3$ (Figure 3(b)) has a spherical shape with the lowest size range and it is uniformly dispersed. The ZnO-2 nanoparticles prepared (Figure 3(c)) have different morphologies and can be seen as clusters of nanoparticles which have high size ranges compared to that of the $\mathrm{ZnO}-3$. This is supported by the XRD data. It is evident that the properties of the $\mathrm{ZnO}$ nanoparticles depend on the conditions applied during their preparations. Such conditions will also affect the efficiency of the photocatalyst during the degradation process.
The activity of the photocatalyst increases with the number of the active sites available. The latter depends on the size and the shape of the particles of the photocatalyst employed [19]. The shapes and the sizes of the $\mathrm{ZnO}$ nanoparticles photocatalysts used were examined by Transmission Electron Microscope (TEM). Figure 4 illustrates the TEM micrographs of the different types of the $\mathrm{ZnO}$ photocatalysts. It can be seen that the particles of these photocatalysts are generally round in shape with different sizes. The sizes of these particles are in nanometer range and they are uniformly distributed; however, some aggregation can also be seen. Regarding the sizes of the particles they have the order $\mathrm{ZnO}-1$ $>\mathrm{ZnO}-2>\mathrm{ZnO}-3$. The XRD data shows a similar trend of the sizes of the particles of these photocatalysts.

3.3. Kinetic Studies of Photodegradation of MTBE. The three photocatalysts $\mathrm{ZnO}-1, \mathrm{ZnO}-3$, and $\mathrm{ZnO}-2$ were used for the photocatalytic degradation of $\mathrm{MTBE}$ in water. $\mathrm{ZnO}-1$ was 


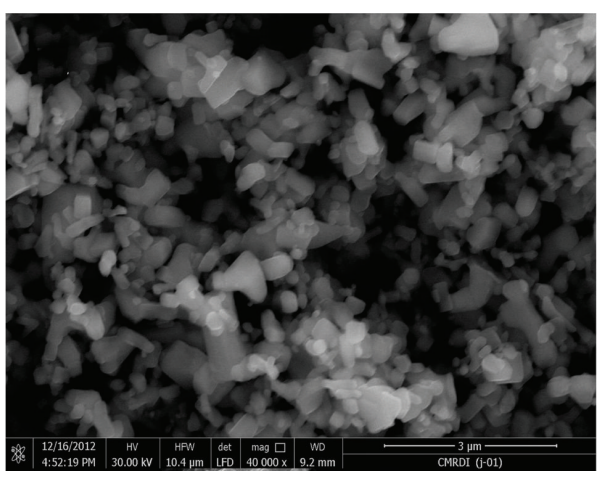

(a)

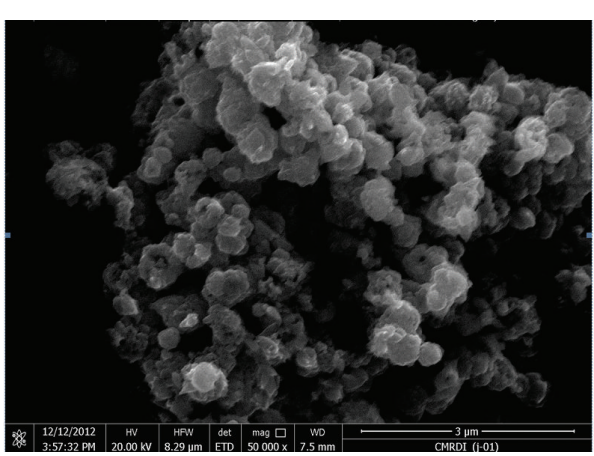

(b)

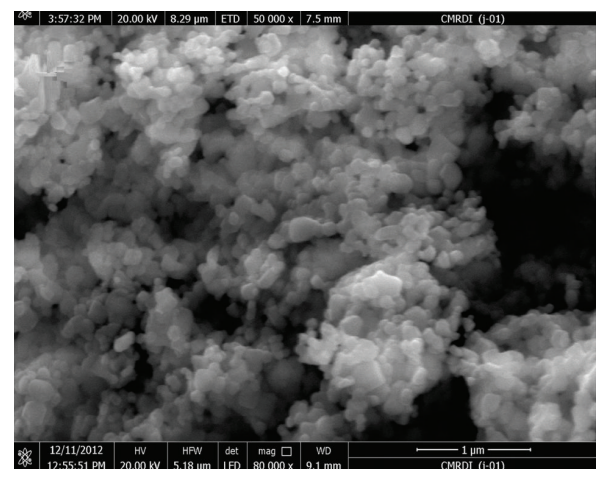

(c)

Figure 3: FESEM of photocatalysts (a) ZnO-1, (b) $\mathrm{ZnO}-2$, and (c) $\mathrm{ZnO}-3$.

found to be more effective in the degradation of MTBE as can be seen from Figure 5. The photocatalytic efficiency was found to be in the order $\mathrm{ZnO}-1>\mathrm{ZnO}-2>\mathrm{ZnO}-3$. From the TEM micrographs, the $\mathrm{ZnO}-3$ having particles of smaller sizes was expected to have better photocatalytic efficiency compared to the other two catalysts. However, it was found that the photocatalytic efficiency of $\mathrm{ZnO}-1$ is higher than the efficiencies of the other two catalysts as can be seen from Figure 4. This can be attributed to the higher number of oxygen vacancies available in the structure of the $\mathrm{ZnO}-1$ which depends on the conditions applied during its preparation [20-22]. Thus, it may be assumed that in case of photocatalytic degradation of aqueous MTBE, the effect of the oxygen vacancies available in the catalytic structure is considered to be more important than the morphology and the surface area of the catalyst.

Most of the photocatalytic reactions follow the kinetic model proposed by Langmuir-Hinshelwood, which relates the rate of photochemical reactions which are proportional to the surface coverage of the photocatalyst [22]. Accordingly,

$$
\text { Rate }=-\left(\frac{d C}{d T}\right)=k_{r} \theta=\left(\frac{k_{r} K C}{1}+K C\right) .
$$

For a very low concentration when $K C \ll 1$

$$
-\ln \left(\frac{C}{C_{0}}\right)=K_{\mathrm{appt}}
$$

where $k_{r}$ is the rate constant, $K$ is the adsorption coefficient of the reactant on the surface of the catalyst, and $C$ is the concentration of the reactant MTBE. When the concentration $C$ is very low, $K C$ becomes negligible compared to 1 . Therefore, the equation represents a first order kinetics $[19,22]$. By plotting $-\ln \left(C_{0} / C\right)$ versus irradiation time for the three catalysts, straight lines were obtained as is shown in Figure 6. This indicates that the kinetics of the photodegradation of MTBE is a first order type. The rate constants obtained from the slopes of the lines in Figure 6 in case of no catalyst, $\mathrm{ZnO}-1, \mathrm{ZnO}-3$, and $\mathrm{ZnO}-2$ are $0.021,0.544,0.337$, and 0.181, respectively (Table 1 ).

\subsection{Effect of $p H$ on the Photocatalytic Degradation of MTBE} Using ZnO-1. Photocatalysts like $\mathrm{ZnO}$ and $\mathrm{TiO}_{2}$ which are commonly used in the photocatalytic degradation reactions are mainly semiconducting metal oxides of amphoteric properties. As a result, the properties of these metal oxides will be affected by variations in the $\mathrm{pH}$ of the reaction medium. The $\mathrm{pH}$ of the medium will also affect the size of the particle aggregates and the distribution of the charges on the surfaces of the particles. Moreover, the dispersion of the particles of the photocatalyst in the medium and the adsorption of MTBE on the surface of the photocatalyst will also be affected by the $\mathrm{pH}$ [23]. The photocatalytic degradation reaction of MTBE using ZnO-1 nanoparticles was performed at different $\mathrm{pH}$ values. The effect of the $\mathrm{pH}$ on the efficiency of the photocatalytic degradation of MTBE is illustrated in Figure 7. 


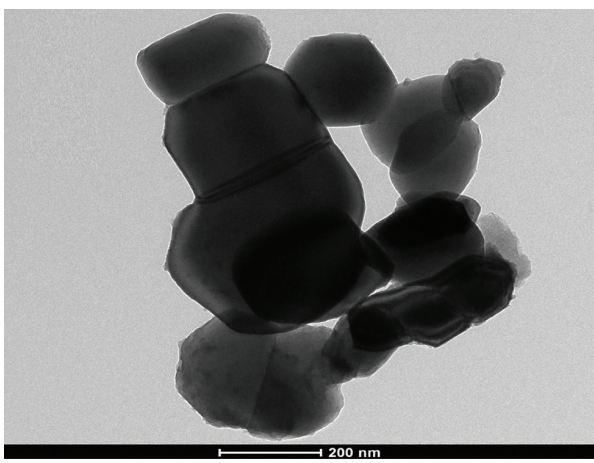

(a)

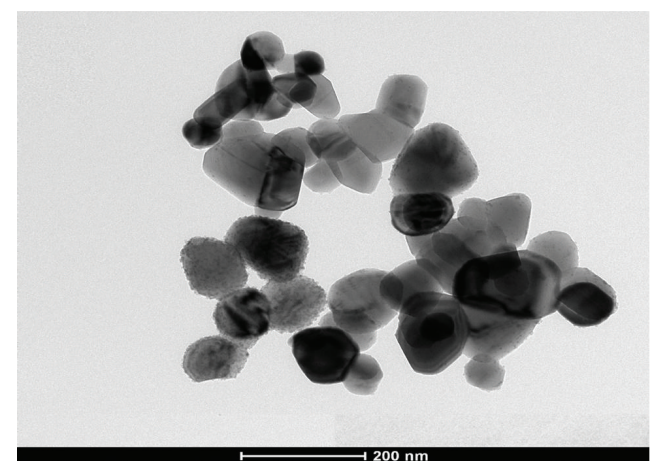

(b)

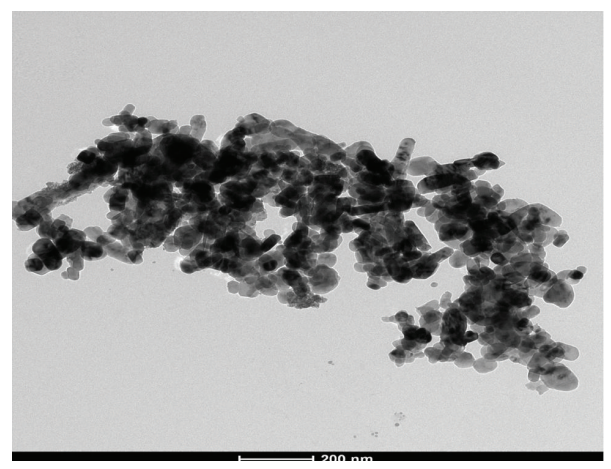

(c)

Figure 4: TEM micrographs of (a) ZnO-1, (b) ZnO-2, and (c) ZnO-3.



FIGURE 5: Photodegradation of MTBE in water using various $\mathrm{ZnO}$ as photocatalysts.

It is obvious from this figure that the $\mathrm{pH}$ has insignificant effect on the efficiency of the photocatalytic degradation of MTBE. However, it has been noted by other researchers that the $\mathrm{pH}$ of the reaction medium plays an important role in the photocatalytic process. For instance, an optimum $\mathrm{pH}$ of 6 was applied during the photodegradation of vanillin using $\mathrm{ZnO}$ as a photocatalyst [24]. In case of the photocatalytic

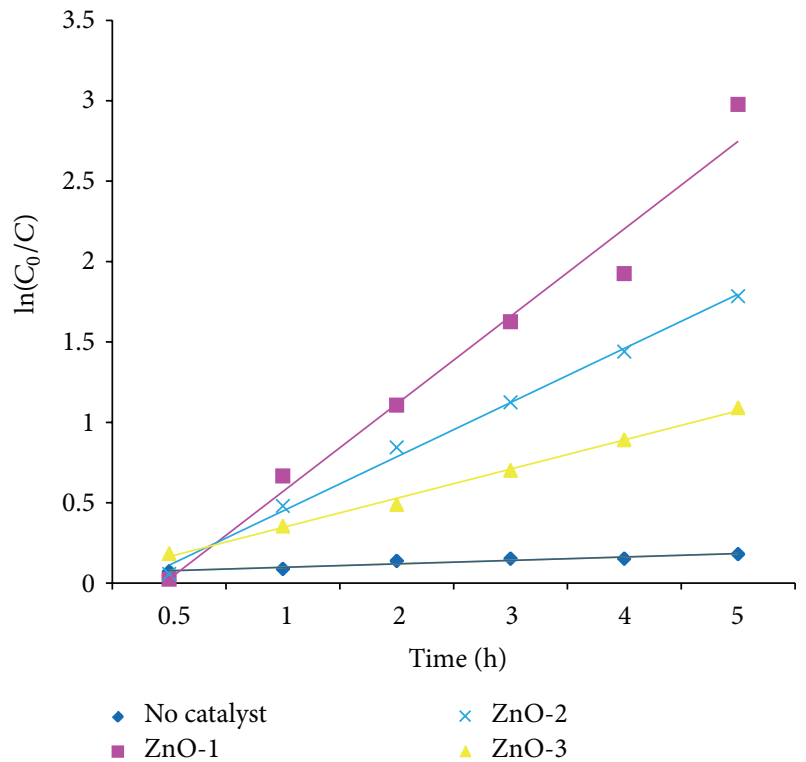

FIGURE 6: First order kinetics of MTBE degradation in presence of $\mathrm{ZnO}$ nanoparticles of different origins photocatalysts.

degradation of MTBE using $\mathrm{ZnO}$ or $\mathrm{TiO}_{2}$, an optimum $\mathrm{pH}$ of 7 was applied [18, 25]. Hu et al. [12] have reported an optimum $\mathrm{pH}$ of 3 for the degradation of $\mathrm{MTBE}$ in $\mathrm{UV} / \mathrm{TiO}_{2}$ system. $\mathrm{Fu}$ et al. [26] found slightly better degradation efficiency 
TABLE 1: Kinetic data of MTBE photodegradation on UV irradiation in presence of catalysts.

\begin{tabular}{lccc}
\hline S. number & Catalyst & $k$ & $R^{2}$ \\
\hline 1 & No catalyst & 0.021 & 0.917 \\
2 & ZnO-1 & 0.544 & 0.973 \\
3 & ZnO-2 & 0.181 & 0.996 \\
4 & ZnO-3 & 0.337 & 0.996 \\
\hline
\end{tabular}

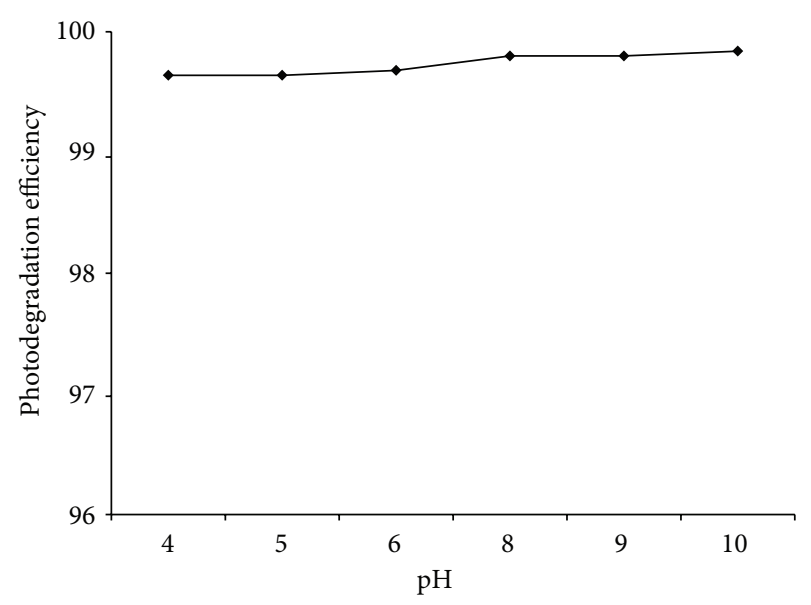

FIGURE 7: Effect of $\mathrm{pH}$ on photodegradation efficiency of $\mathrm{ZnO}-1$.

of methylene blue when the $\mathrm{pH}$ was changed from acidic to the neutral value. However, in the alkaline region the efficiency of degradation has increased by many folds. In solutions of higher $\mathrm{pH}$ values, the recombination of the photoexcited electron-hole pair is reduced, and as a result the photodegradation efficiency increases. This efficiency also increases at higher $\mathrm{pH}$ values due to the fact that more $\mathrm{OH}^{-}$and ${ }^{\circ} \mathrm{OH}$ will be available. However, in case of $\mathrm{TiO}_{2}$, a decrease in the photocatalytic efficiency has been observed at higher $\mathrm{pH}$ values. This could be attributed to the repulsion phenomenon between the hydroxyl ions and the negatively charged surface of $\mathrm{TiO}_{2}[27,28]$. It seems that the effect of $\mathrm{pH}$ on the photocatalytic degradation of MTBE requires further investigations to be undertaken.

\section{Conclusions}

The potentialities of the $\mathrm{ZnO}$ nanoparticles of different particle sizes in the photocatalytic degradation of MTBE in water were investigated. $\mathrm{ZnO}-1$ nanoparticles were found to be very effective in the photocatalytically degrading of MTBE even at different $\mathrm{pH}$ values. Oxygen vacancies are expected to play a dominating role over the morphology and the surface area. The photocatalytic degradation of aqueous MTBE catalyzed by $\mathrm{ZnO}$ nanoparticles was observed to follow Hinshelwood first order kinetics.

\section{Acknowledgment}

The authors wish to acknowledge the support by King Abdul Aziz City for Science and Technology (KACST) through the Science \& Technology Unit at Umm Al-Qura University for funding through Project no. 10-wat1240-10 as part of the National Science, Technology and Innovation Plan.

\section{References}

[1] M. J. Day, R. F. Reinke, and J. A. M. Thomson, "Fate and transport of fuel components below slightly leaking underground storage tanks technical note," Environmental Forensic, vol. 2, pp. 21-28, 2001.

[2] C. Guillard, N. Charton, and P. Pichat, "Degradation mechanism of t-butyl methyl ether (MTBE) in atmospheric droplets," Chemosphere, vol. 53, no. 5, pp. 469-477, 2003.

[3] Y. Zang and R. Farhood, "Effects of hydrogen peroxide concentration and ultraviolet light intensity on methyl tert-butyl ether degradation kinetics," Chemical Engineering Science, vol. 60, no. 6, pp. 1641-1648, 2005.

[4] E. Selli, C. L. Bianchi, C. Pirola, and M. Bertelli, "Degradation of methyl tert-butyl ether in water: effects of the combined use of sonolysis and photocatalysis," Ultrasonics Sonochemistry, vol. 12, no. 5, pp. 395-400, 2005.

[5] J. Araña, A. Peña Alonso, J. M. Doña Rodríguez, J. A. Herrera Melián, O. González Díaz, and J. Pérez Peña, "Comparative study of MTBE photocatalytic degradation with $\mathrm{TiO}_{2}$ and $\mathrm{Cu}$ $\mathrm{TiO}_{2}$, , Applied Catalysis B, vol. 78, no. 3-4, pp. 355-363, 2008.

[6] C. Baus, H. Hung, F. Sacher, M. Fleig, and H.-J. Brauch, "MTBE in drinking water production-occurrence and efficiency of treatment technologies," Acta Hydrochimica et Hydrobiologica, vol. 33, no. 2, pp. 118-132, 2005.

[7] A. Asadi and M. Mehrvar, "Degradation of aqueous methyl tertbutyl ether by photochemical, biological, and their combined processes," International Journal of Photoenergy, vol. 2006, Article ID 19790, 7 pages, 2006.

[8] F. Fayolle, A. François, L. Garnier et al., "Limitations in MTBE biodegradation," Oil and Gas Science and Technology, vol. 58, no. 4, pp. 497-504, 2003.

[9] N. Y. Fortin, M. Morales, Y. Nakagawa, D. D. Focht, and M. A. Deshusses, "Methyl tert-butyl ether (MTBE) degradation by a microbial consortium," Environmental Microbiology, vol. 3, no. 6, pp. 407-416, 2001.

[10] M. Bertelli and E. Selli, "Kinetic analysis on the combined use of photocatalysis, $\mathrm{H}_{2} \mathrm{O}_{2}$ photolysis, and sonolysis in the degradation of methyl tert-butyl ether," Applied Catalysis B, vol. 52, no. 3, pp. 205-212, 2004.

[11] M. S. M. Chan and R. J. Lynch, "Photocatalytic degradation of aqueous methyl tert-butyl ether (MTBE) in a supportedcatalyst reactor," Environmental Chemistry Letter, vol. 1, no. 3, pp. 157-160, 2003.

[12] Q. Hu, C. Zhang, Z. Wang et al., "Photodegradation of methyl tert-butyl ether (MTBE) by $\mathrm{UV} / \mathrm{H}_{2} \mathrm{O}_{2}$ and $\mathrm{UV} / \mathrm{TiO}_{2}$," Journal of Hazardous Materials, vol. 154, no. 1-3, pp. 795-803, 2008.

[13] B. Dindar and S. Içli, "Unusual photoreactivity of zinc oxide irradiated by concentrated sunlight," Journal of Photochemistry and Photobiology A, vol. 140, no. 3, pp. 263-268, 2001.

[14] S. Devipriya and S. Yesodharan, "Photocatalytic degradation of pesticide contaminants in water," Solar Energy Materials and Solar Cells, vol. 86, no. 3, pp. 309-348, 2005. 
[15] A. A. Aal, S. A. Mahmoud, and A. K. Aboul-Gheit, "Nanocrystalline $\mathrm{ZnO}$ thin film for photocatalytic purification of water," Materials Science and Engineering C, vol. 29, no. 3, pp. 831-835, 2009.

[16] B. Pal and M. Sharon, "Enhanced photocatalytic activity of highly porous $\mathrm{ZnO}$ thin films prepared by sol-gel process," Materials Chemistry and Physics, vol. 76, no. 1, pp. 82-87, 2002.

[17] S. S. Shinde, P. S. Shinde, C. H. Bhosale, and K. Y. Rajpure, "Zinc oxide mediated heterogeneous photocatalytic degradation of organic species under solar radiation," Journal of Photochemistry and Photobiology B, vol. 104, no. 3, pp. 425-433, 2011.

[18] A. Eslami, S. Nasseri, B. Yadollahi et al., "Photocatalytic degradation of methyl tert-butyl ether (MTBE) in contaminated water by ZnO nanoparticles," Journal of Chemical Technology and Biotechnology, vol. 83, no. 11, pp. 1447-1453, 2008.

[19] K. Hayat, M. A. Gondal, M. M. Khaled, S. Ahmed, and A. M. Shemsi, "Nano ZnO synthesis by modified sol gel method and its application in heterogeneous photocatalytic removal of phenol from water," Applied Catalysis A, vol. 393, no. 1-2, pp. 122-129, 2011.

[20] J. Liqiang, Q. Yichun, W. Baiqi et al., "Review of photoluminescence performance of nano-sized semiconductor materials and its relationships with photocatalytic activity," Solar Energy Materials and Solar Cells, vol. 90, no. 12, pp. 1773-1787, 2006.

[21] S.-Z. Kang, T. Wu, X. Li, and J. Mu, "A facile gelatinassisted preparation and photocatalytic activity of zinc oxide nanosheets," Colloids and Surfaces A, vol. 369, no. 1-3, pp. 268271, 2010.

[22] W.-J. Huang, G.-C. Fang, and C.-C. Wang, "A nanometer-ZnO catalyst to enhance the ozonation of 2,4,6-trichlorophenol in water," Colloids and Surfaces A, vol. 260, no. 1-3, pp. 45-51, 2005.

[23] P. R. Gogate and A. B. Pandit, "A review of imperative technologies for wastewater treatment I: oxidation technologies at ambient conditions," Advances in Environmental Research, vol. 8, no. 3-4, pp. 501-551, 2004.

[24] M. Qamar and M. Muneer, "A comparative photocatalytic activity of titanium dioxide and zinc oxide by investigating the degradation of vanillin," Desalination, vol. 249, no. 2, pp. 535540, 2009.

[25] A. Eslami, S. Nasseri, B. Yadollahi, A. Mesdaghinia, F. Vaezi, and R. Nabizadeh, "Removal of methyl tert-butyl ether (MTBE) from contaminated water by photocatalytic process," Iranian Journal of Public Health, vol. 38, no. 2, pp. 18-26, 2009.

[26] D. Fu, G. Han, Y. Chang, and J. Dong, "The synthesis and properties of $\mathrm{ZnO}$-graphene nano hybrid for photodegradation of organic pollutant in water," Materials Chemistry and Physics, vol. 132, no. 2-3, pp. 673-681, 2012.

[27] I. K. Konstantinou and T. A. Albanis, " $\mathrm{TiO}_{2}$-assisted photocatalytic degradation of azo dyes in aqueous solution: kinetic and mechanistic investigations: a review," Applied Catalysis B, vol. 49, no. 1, pp. 1-14, 2004.

[28] S. Bekkouche, M. Bouhelassa, N. Hadj Salah, and F. Z. Meghlaoui, "Study of adsorption of phenol on titanium oxide $\left(\mathrm{TiO}_{2}\right)$," Desalination, vol. 166, no. 1-3, pp. 355-362, 2004. 

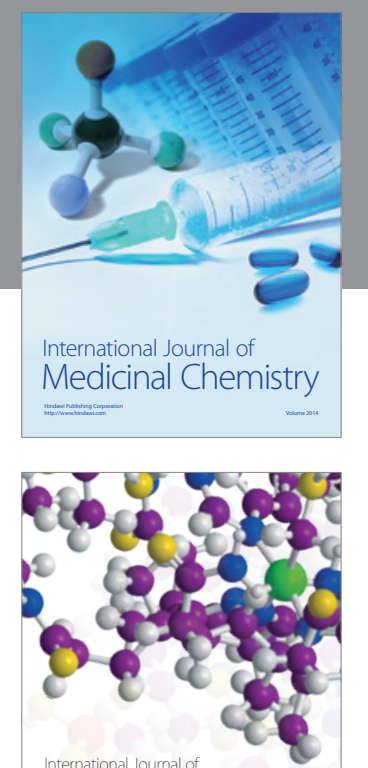

\section{Carbohydrate} Chemistry

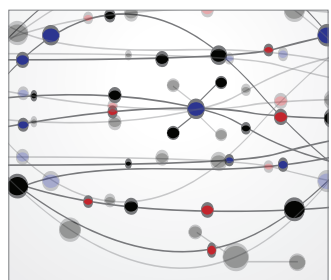

The Scientific World Journal
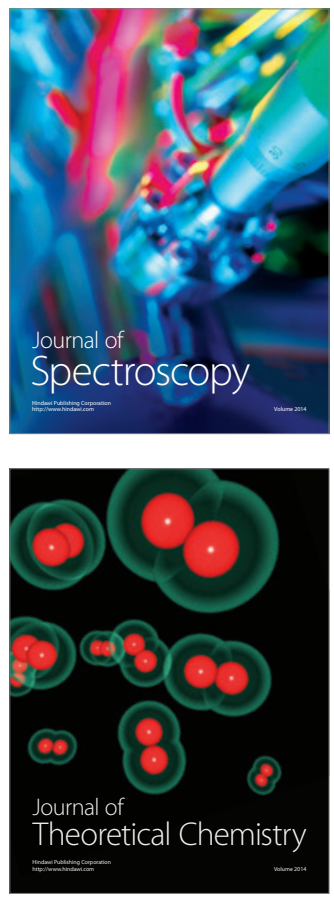
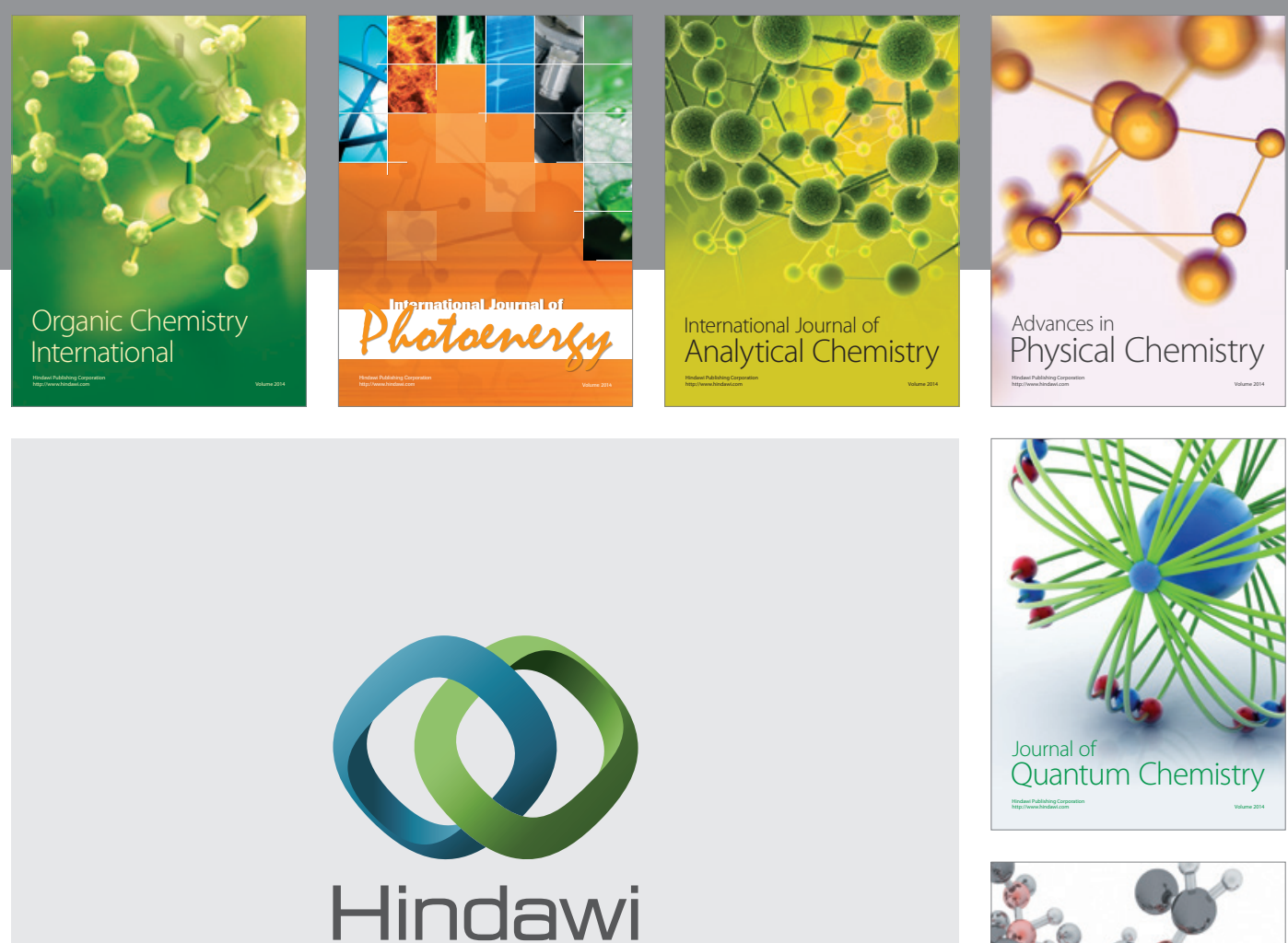

Submit your manuscripts at

http://www.hindawi.com

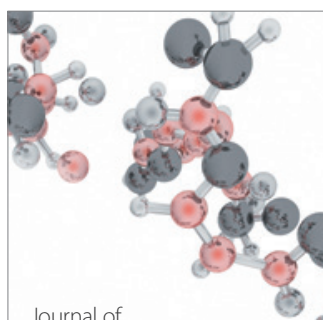

Analytical Methods

in Chemistry

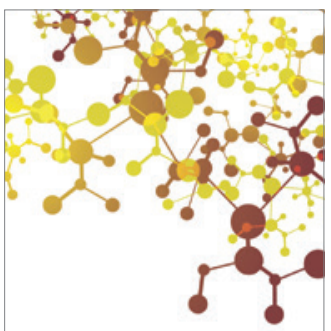

Journal of

Applied Chemistry



Inorganic Chemistry
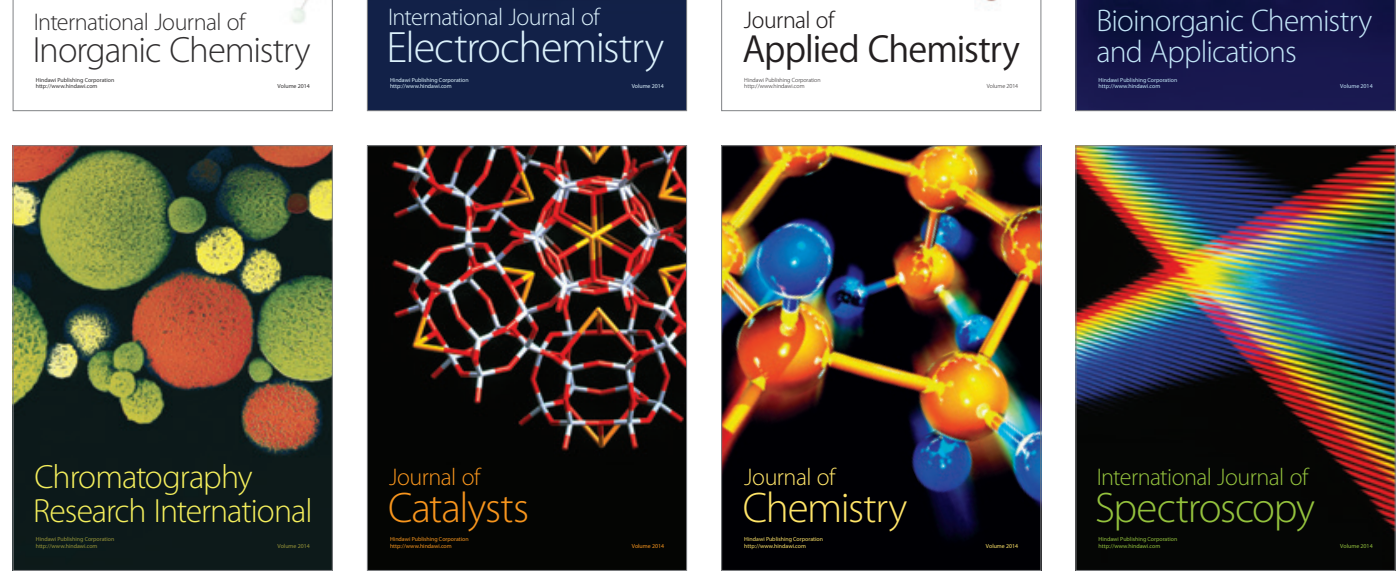